\title{
From Dreamweaver to Drupal: A University Library Website Case Study
}

Jesi Buell and

Mark Sandford

\begin{abstract}
In 2016, Colgate University Libraries began converting their static HTML website to the Drupal platform. This article outlines the process librarians used to complete this project using only in-house resources and minimal funding. For libraries and similar institutions considering the move to a content management system, this case study can provide a starting point and highlight important issues.
\end{abstract}

\section{INTRODUCTION}

The literature available on website design and usability is predominantly focused on business or marketing websites. What separates library websites from other informational or commercial websites is the complexity of the information architecture - they contain both intricate informational and transactional functions. Website managers need to maintain congruity between many interrelated but disparate tools in a singular interface and navigational system. Libraries are also often challenged with finding individuals who possess the appropriate skills to build and maintain a secure, accessible, attractive, and easy-to-use website. In contrast to libraries, commercial companies employ a team of designers, developers, content managers, and specialists to triage internal and external issues. They can also spend months or years perfecting a website and, of course, all these factors have great costs associated with them.

Given that many commercial websites need a team of highly skilled workers with copious time and funding, how can librarians be expected to give their patrons similar experiences to sites like Google? This case study will outline how a small team of librarians completely overhauled their fragmented, Dreamweaver-based website to a more secure, organized, and appealing open-source platform with Drupal within a tight timeline and very few financial consequences. It includes a timeline of major milestones in the appendix.

\section{GOALS AND OBJECTIVES}

The first necessity for restructuring the Colgate University Libraries' website was building a team that had the skills and knowledge necessary to perform this task. The website overhaul was spearheaded by Jesi Buell, instructional design and web librarian, and Mark Sandford, systems librarian. Buell has a user experience (UX) design and editing background while Sandford has systems, cataloging, and server experience. They were advised by Web Development Committee (WDC) members Cindy Li, associate director of library technology and digital initiatives, and Debbie Krahmer, digital learning and media librarian. Together, the group understood trends in digital librarianship, the needs of the Libraries' patrons, as well as website and catalog design and

Jesi Buell (jbuell@colgate.edu) is Instruction and Design and Web Librarian and Mark Sandford (msandford@colgate.edu) is Systems Librarian at Colgate University, Hamilton, New York. 
maintenance.

The first thing the WDC did was outline its goals and objectives, and this documented weaknesses the group wanted to address with a new website. The WDC identified four main improvements Colgate Libraries needed to make to the website:

\section{Improve Design}

Colgate Libraries' old website suffered from varied design and language use across pages and various tools (LibGuides, catalog, etc.). This led to an inconsistent and often frustrating user experience and detracted from the user's sense of a single, cohesive website. The WDC also wanted to improve and update the aesthetic quality of the website. While many of these changes could have been made with an overhaul of the existing site, the WDC would have still needed to address the underlying cause. Responsibility for content was decentralized, and content creation relied too heavily on technical expertise with Dreamweaver. Further, the ad hoc nature of the content - the product of years of "fitting in" content without a holistic approach - meant that changes to visual style could not be accomplished by changing a single CSS file. There were far too many exceptions to make changes simply.

\section{Improve Usability}

The WDC needed to make sure all the webpages were responsive and accessible. A restructuring of layout and information architecture (IA) was also necessary to improve findability of resources. On the old site, some content was hidden behind several layers of links. With no platform to ensure or enforce accessibility standards, website managers had to trust that all content creators were conscious of best practices or, failing that, pages had to be re-edited to improve accessibility.

\section{Improve Content Creation and Governance}

A common source of library staff frustration was the authoring experience using Dreamweaver. There was no way to track when a webpage was changed or see who had made those changes. Situations occurred where content was deleted or changed in error, and no one else knew until a patron discovered a mistake. Staff could also mistakenly push out outdated versions of pages. It was not an ideal situation, and it was impossible for an individual (the web librarian) to monitor hundreds of pieces of content for daily changes to check for accuracy. The only other option would be narrow access to only those on the WDC, but that would mean everyone had to wait for the web librarian to push content live, which would also be frustrating. Beyond the security and workflow issues, many of the library staff felt uncomfortable adding or editing content because Dreamweaver requires some coding knowledge (HTML, CSS, JavaScript). Therefore, the group wanted to install a content management system (CMS) that provided a WYSIWYG (What You See Is What You Get) content editor so that no coding knowledge would be needed.

\section{Unite Disparate Sites (Website, Blog, and Database List) under One Updated URL on a Single Secure Server}

Colgate Libraries' website functionality suffered from what Marshall Breeding describes as "a fragmented user experience." ${ }^{1}$ The Libraries website's main address was http://exlibris.colgate.edu. However, different tools lived under other URLs - one for a blog, another for the database list, yet another still for the mobile site librarians had to maintain 
because the main website was not responsive. Additionally, some portions of the website had been set up on other servers because of various limitations in the Windows.Net environment and inhouse skills. This was further complicated by the fact that most specialized interactivity or visual components had to be created from scratch by existing staff. The Libraries' blog was on an externally hosted WordPress site, and the database A-Z list was on a custom-coded PHP page. A unified domain would make usage statistics easier to track and analyze. Additionally, it would eliminate the need for multiple credentials for the various external sites. Custom code, be it in PHP, .Net, or any other language, also needs to be regularly updated as new security vulnerabilities arise. ${ }^{2}$ Moving to a well-maintained CMS would help alleviate that burden.

By establishing goals and objectives, the WDC had identified that it wanted a CMS to help with better governance, easier maintenance, and ways to disperse web maintenance responsibilities across library faculty. It was important to choose a CMS platform that offered a WYSIWYG editor so that content authoring did not require coding knowledge. Additionally, the group wanted to update the site's aesthetic and navigational designs.

The WDC also decided that this was the optimal time to introduce a discovery layer (since all these changes would be one entirely new experience for Colgate users) rather than smaller, continual changes that would require users to keep readjusting how they used the website. The backend complexity of updating both the website platform and implementing a discovery layer required abundant and detailed planning. However, while there was a lot of overlap in the preparatory work for implementing the discovery layer as well the CMS, this article will focus primarily on the CMS.

\section{PLANNING}

After the WDC had detailed goals and objectives, and the proposal to update the Libraries' website platform was accepted by library faculty, the group had to take several steps to plan the implementation. The first steps in planning dealt with analysis.

\section{Content Analysis}

The web librarian conducted a content analysis of the existing website. Using Microsoft Excel to document the pages and the Omni Group's Omnigraffle to organize the spreadsheet into a diagram, she cataloged each page and the navigation that connected that page to other pages. This can be extremely laborious but was necessary because some content was inherited from past employees over the course of a decade, and no one knew exactly what content was live on the website. This visual representation allowed for content creators to see redundancy in both content and navigation. It also made it easy for them to identify old content and combine or reorder pages.

\section{Needs Analysis}

The WDC wanted to make sure it considered more than the content creators' needs. This group surveyed Colgate faculty, staff, and students to learn what they would like to see improved or changed. The web librarian conducted several UX studies with both students and faculty, and this elucidated several key areas in need of improvement. 


\section{Peer Analysis}

Peer Analysis involves thoroughly investigating peer institution's websites to analyze how they organize both their content and their site navigation. It also gives insight into what other services and tools they provide. It is important to choose institutions similar in size and academic focus. Colgate University is a small, liberal arts institution that only serves an undergraduate population, so the Libraries would not seek to emulate a large university that serves graduate populations or distance learners. Peer analysis is an excellent opportunity to see where a website is not measuring up to other websites as well as to borrow ideas from peers to customize for your specific patrons.

\section{Evaluating Platforms}

Now that the group knew what the Libraries had and what the Libraries wanted from our web presence, it was time to evaluate the available options. This involved evaluating CMS products and discovery layer platforms. The WDC researched different CMSs and listed positives and negatives. Ultimately, the group determined that Drupal best satisfied the majority of Colgate's identified needs. A separate committee was formed to evaluate the major discovery-layer services with the understanding that any option could be integrated into the main website as a search box.

\section{Budgeting}

As free, open-source software, Drupal does not require a subscription or licensing fee. Campus IT provided a virtual server for the website at no cost to the Libraries. Budgeting was organized by the associate director of library technology and digital initiatives and the university librarian. Money was set aside in case a consultant or developer was needed, but the web and systems librarians were able to execute the conversion from Dreamweaver to Drupal without external support. If future development support is needed for specific projects, it can be budgeted for and purchased as needed.

The last step was creating a timeline defining achievable goals, ownership (who oversees completing the goal and who needs to be involved with the work), and date of completion.

\section{TIMELINE}

The timeline was outlined as follows:

\section{October 2015-January 2016}

Halfway through the Fall 2015 semester, the WDC began to create a proposal for changes to be made to the website. This proposal would be submitted to the university librarian for consideration by December 1 . In the meantime, the web librarian completed a content inventory, peer analysis, and UX studies. She also gathered faculty and staff feedback on the current website through suggestion-box commentary, one-on-one interviews, online questionnaires, and anecdotal stories. By the deadline for the proposal, this additional information was condensed and presented to the university librarian.

After incorporating suggested changes made by the university librarian, the WDC was able to present both the proposal and results from various studies to the library faculty on January 4 , 
2016. At the end of the meeting, the faculty voted to move forward and adopt the proposed changes.

\section{February 2016}

February was spent meeting with stakeholders, both internal and external to the Libraries, to gather concerns, necessary content, and ideas for improvements. The WDC members shared the responsibility of running these meetings.

All members from the following departments were interviewed: Research and Instruction, Borrowing Services, Acquisitions, Library Administration, Cataloging, Government Documents, Information Literacy, Special Collections and University Archives, and the Science Library. Together, the WDC also met with members from IT and Communications.

It was vital that these sessions identify several components. First, what content was important to retain on the new site, and why? The act of justification made stakeholders evaluate whether the information was necessary and useful to the Libraries' users. The WDC also asked the stakeholders to identify changes they wanted to see made to the website. The answers ranged from minor aesthetic tweaks to major navigational overhauls. Last, it was important to understand how specific changes might impact workflows and functionality for tools outside Colgate Libraries' own website. For example, the WDC had to update information with the Communications department so that the Libraries' website would be findable on the university's app.

All the answers the WDC received were compiled into a report, and the web librarian used this information to inform design decisions moving forward.

\section{March 2016}

While the associate director of library technology and digital initiatives coordinated demos from discovery layer vendors, the WDC also met to choose the final template from three options designed by the web librarian. The web and systems librarians also met to create a list of developers in case assistance was needed in the development of the Drupal site. The WDC team researched potential developers and inquired about their pricing.

The web librarian began to create wireframe templates of the different types of pages and page components (homepage, hours blocks, blogs, forms, etc.). She also began transferring existing content from the old website to the new website. This process, in addition to the development of new content identified by stakeholders, was to be completed by mid-summer.

Meanwhile, the systems librarian began to consolidate the external sites under Drupal to the extent possible. While LibGuides lives externally to Drupal and maintains its own URL that the Libraries' website links out to, he was able to bring the database A-Z list, blog, and analytics into the Drupal platform. This entailed setting up new content types in Drupal to accommodate various functional requirements for the A-Z list and assist in creating pages to search for and display database information. 


\section{April-May 2016}

Drupal allows for various models of permissions and authentication. By default, accounts can be created within the Drupal system and roles and permissions assigned to individuals as needed. The LDAP (Lightweight Directory Access Protocol) module allowed us to tie authentication to university accounts and includes the ability to tie Drupal permissions to Active Directory roles and groups. Connecting Drupal to the university LDAP server required the assistance of IT Infrastructure staff but was straightforward. IT staff provided the connection information for the Drupal module's configuration and created a resource account for the Drupal module to use to connect to the LDAP service. As currently implemented, the LDAP module simply verifies credentials and, if a local Drupal account does not exist, creates one for the user. Permissions for staff are added to accounts after account creation as needed as a part of the onboarding process.

Permissions in Drupal can be highly granular. Since one of the goals of the migration to Drupal was to simplify maintenance of the website, the WDC decided to begin with a relatively simple, permissive approach. Currently, all library staff can edit any page. Because of Drupal's ability to track and revert changes easily, undoing a problematic edit is a simple procedure, and because all changes are tied to an individual login, problems can be addressed through training as needed. The WDC discussed a more fragmented approach that tied editing privileges to specific parts of the site but decided against it. The WDC team felt it was better to begin with the presumption of trustworthiness, expecting staff to only make changes to pages they were personally responsible for. Additionally, trying to divide the site into logical pieces, then accounting for the inevitable exceptions, would be complicated and time-consuming. The WDC reserved the right to begin restricting permissions in the future, but thus far this has proven unnecessary.

\section{July-August 2016}

As the Libraries ramped up to the official launch, it was crucial to educate the library faculty and staff so they could become independent back-end content creators. Both the web and systems librarians held multiple training sessions for the Libraries employees so that everyone felt comfortable both editing and generating content.

The associate director of library technology and digital initiatives drafted a campus-wide email announcing the new website and discovery layer at this point. It was sent out a month in advance of the official launch.

The new website launched in two parts. The soft launch occurred on August 1, 2016. The web and systems librarians set up a link to the new website on the old site so that users could choose between getting acclimated to the new website or using the tool they were used to in the frantic weeks leading up to the beginning of the semester. August 15, 2016, was the official launch. At this point, the http://exlibris.colgate.edu Dreamweaver-based website was retired, and IT redirected all traffic heading to the old URL to the new Drupal-based website at http://cul.colgate.edu. Because Drupal's URL structure and information architecture differed from the old website, the WDC decided that mapping every page on the old site to the new one would be too time consuming. While it was acknowledged that this may cause some disruption (as it would break existing links), it seemed necessary for keeping the project moving forward. Library staff updated all external links possible. The Google search operator "inurl" allowed us to identify other sites 
outside the Libraries' control that pointed to the old website. The WDC reached out to the maintainers of those few sites as appropriate.

The biggest risk the Libraries took by not redirecting all URLs to the correct content was the potential to disrupt faculty who had bookmarked content or had direct URLs in course materials. However, the WDC team received very few complaints about the new site, and most users agreed that the improvements to the site far outweighed any temporary inconveniences caused by it. If nothing else, the simplified architecture made finding content easier, so direct links and bookmarks became far less important than they once were.

\section{IMPLEMENTATION AND FUTURE STEPS}

By strictly following the timeline and working closely together, the web librarian and systems librarian were able to launch Colgate Libraries' new website in time for the 2016 Fall semester. The WDC team was able to pull off this feat within eight months without spending any extra money. The timeline above only gives a high-level view of the steps the WDC took to accomplish this task. The librarians who worked on this project cannot overemphasize the complexity of this endeavor, especially with a small team. However, a website conversion is feasible with organization, time, and with the online support the Drupal community provides (especially the community of libraries on the Drupal platform). It is also critical to have in-house personnel that have technical (coding and server-side) knowledge, project management knowledge, and information architecture and design knowledge.

The response from incoming and returning students and faculty to the updated look and improved usability of the Libraries' digital content was overwhelmingly positive. Following best design practices, in January 2017 more UX testing was conducted with student and teaching faculty participants to gauge their reactions to the new website. ${ }^{3}$ Users overwhelmingly found the new website to be both more aesthetically pleasing and usable than the old website.

On the back end, the Libraries' content is now more secure, responsive, and accessible because the Libraries are using a CMS. Library faculty and staff have been able to add or remove content that they are responsible for, but the website can still maintain a consistent look and feel across all pages. Governance has been improved exponentially as library staff have been able to easily and quickly contribute to the website's content without administrative delays.

As the team moves forward, the WDC plans to investigate different advanced Drupal tools, implementing an intranet, and better leveraging Google Analytics. As with all library endeavors, improvement requires continued effort and attention. 


\section{APPENDIX: DETAILED TIMELINE}

1. October 2015

a. Began discussion with WDC to create proposal for website changes (web librarian)

2. November-December 2015
a. Complete content inventory (web librarian)
b. Complete peer analysis (web librarian)
c. Complete UX studies (web librarian)
d. Gather faculty and staff feedback on current website (web librarian)

3. December 1,2015

a. Submit proposal to change from Dreamweaver to Drupal to university librarian for consideration and approval (web librarian)

4. January 4, 2016

a. Submit revised proposal to library faculty for consideration and approval (web librarian)

5. January 2016
a. Set up test Drupal site (systems librarian)

6. February 2016

a. Complete meetings with departments to gather feedback on concerns, content, and ideas for improvements (library department meetings were split among WDC members)

7. March 2016
a. Demo PRIMO, Ex Libris, and Summon for library faculty and staff consideration (associate director of library technology and digital initiatives)
b. From three options, choose template for our website (web librarian-approval by the WDC and then the library faculty)
c. Create list of developers in case we need assistance (web librarian and systems librarian)
d. Create wireframe templates for homepage (web librarian)
e. Begin transferring content from old website to new website and create new content with other stakeholders - to be completed by mid-summer (web librarian)
f. Begin consolidating multifarious external sites under Drupal as much as possible (systems librarian)

8. April 2016
a. Get Drupal working with the LDAP (systems librarian)
b. Agree on permissions and roles for back-end users (systems librarian-with approval by WDC)
c. Agree on discovery layer choice (associate director of library technology and digital initiatives)
d. Meet with outside stakeholders-Communications, IT, administration

9. May 2016

10. July 2016
a. Integrate discovery layer search (systems librarian)
a. Provide training for library faculty and staff as back-end content creators (web librarian)


b. Prepare campus-wide email to announce new website and discovery layer with our new URL (associate director of library technology and digital initiatives and web librarian)

\section{August 1, 2016}

a. Set up a link on our old site (http://exlibris.colgate.edu) so for two weeks users could choose between using the old interface or start getting acclimated to the new website before the Fall semester started (systems librarian)

\section{August 15, 2016}

a. OFFICIAL LAUNCH-We retire our http://exlibris.colgate.edu Dreamweaver-based website and redirect all traffic headed to our old URL to our new Drupal-based website at http://cul.colgate.edu (systems librarian)

13. September-October 2016

a. Update and get approval from library faculty for a new web style guide and governance guide (web librarian)

14. January 2017

a. Conduct UX studies of students and faculty to see how people are using both the new website and the new discovery layer; gather feedback and ideas for improvement (web librarian)

\section{BIBLIOGRAPHY}

Breeding, Marshall. "Smarter libraries through technology: strategies for creating a unified web presence." Smart Libraries Newsletter 36, 11 (November 2016): 1-2. General OneFile (accessed August 3, 2017).

http://go.galegroup.com/ps/i.do?p=ITOF\&sw=w\&v=2.1\&it=r\&id=GALE\%7CA471553487.

Naudi, T. "Nearly all websites have serious security vulnerabilities--new research shows." Database and Network Journal 45, 4 (2015): 25. General OneFile (accessed August 3, 2017). http://bi.galegroup.com/essentials/article/GALE\%7CA427422281.

Raward, R. “Academic Library Website Design Principles: Development of a Checklist." Australian Academic \& Research Libraries 32, 2 (2001): 123-36.

http://dx.doi.org/10.1080/00048623.2001.10755151

${ }^{1}$ Marshall Breeding, "Smarter Libraries through Technology: Strategies for Creating a Unified Web Presence," Smart Libraries Newsletter 36, no. 11 (November 2016): 1-2. General OneFile.

2 Tamara Naudi, “Nearly All Websites have Serious Security Vulnerabilities-New Research Shows," Database and Network Journal 45, no. 4 (2015): 25. General OneFile.

3 Roslyn Raward, “Academic Library Website Design Principles: Development of a Checklist," Australian Academic \& Research Libraries 32, no. 2 (2001): 123-36. 